University of Texas at El Paso

ScholarWorks@UTEP

7-2019

\title{
Unexpected Empirical Dependence of Calf Gender on Insemination Time: System-Based Explanation
}

\author{
Griselda Acosta \\ The University of Texas at El Paso, gvacosta@miners.utep.edu \\ Eric Smith \\ The University of Texas at El Paso, esmith2@utep.edu \\ Vladik Kreinovich \\ The University of Texas at El Paso, vladik@utep.edu
}

Follow this and additional works at: https://scholarworks.utep.edu/cs_techrep

Part of the Applied Mathematics Commons

Comments:

Technical Report: UTEP-CS-19-69

Published in Applied Mathematical Sciences, 2019, Vol. 13, No. 14, pp. 681-684.

\section{Recommended Citation}

Acosta, Griselda; Smith, Eric; and Kreinovich, Vladik, "Unexpected Empirical Dependence of Calf Gender on Insemination Time: System-Based Explanation" (2019). Departmental Technical Reports (CS). 1334.

https://scholarworks.utep.edu/cs_techrep/1334

This Article is brought to you for free and open access by the Computer Science at ScholarWorks@UTEP. It has been accepted for inclusion in Departmental Technical Reports (CS) by an authorized administrator of ScholarWorks@UTEP.For more information, please contact Iweber@utep.edu. 


\title{
Unexpected Empirical Dependence of Calf Gender on Insemination Time: System-Based Explanation
}

\author{
Griselda Acosta ${ }^{1}$, Eric Smith ${ }^{2}$, and Vladik Kreinovich ${ }^{3}$ \\ ${ }^{1}$ Department of Electrical and Computer Engineering \\ ${ }^{2}$ Department of Industrial, Manufacturing, and \\ Systems Engineering \\ ${ }^{3}$ Department of Computer Science \\ University of Texas at El Paso \\ $500 \mathrm{~W}$. University \\ El Paso, TX 79968, USA \\ gvacosta@miners.utep.edu, esmith2@utep.edu,vladik@utep.edu
}

\begin{abstract}
To improve the efficiency of artificial insemination, farmers equip cows with sensors, based on which a computer system determines the cow's insemination window. Analysis of the resulting calves showed an unexpected dependence of the calf's gender on the insemination time: cows inseminated earlier in their window mostly gave birth to female calves, while cows inseminated later in their window mostly gave birth to males. In this paper, we provide a general system-based explanation for this phenomenon.
\end{abstract}

\section{Formulation of the Problem}

Unexpected empirical fact. Computer-based systems are ubiquitous. For example, farmers use sensors to identify cows in heat - they then apply artificial insemination to these particular cows, thus guaranteeing that all the inseminated cows will become pregnant.

When analyzing the results of applying this technique, researchers found out an unexpected phenomenon - that the gender of the resulting calves depends on the insemination time:

- for cows inseminated at the very beginning of their sixteen-hour insemination window, most resulting calves are female (to be more precise, about $70 \%$ ); while 
- for cows inseminated during the later part of their sixteen-hour insemination window, most resulting calves are male;

see, e.g., [1] and references therein.

What we do in this paper. In this paper, we provide a natural system-based explanation for this newly discovered phenomenon.

\section{Our Explanation}

What would be a perfect mix of cow genders. Artificial insemination is a reasonably recent process. Until then, cows were always inseminated by the bulls. From this viewpoint, to understand why cows sometimes give birth to male calves and sometimes to female calves, we need to understand what proportion of cows and bulls would be perfect for such a mixed cows-and-bulls herd.

From the biological viewpoint, each species aims to reproduce as much as possible - as much as the food and other resources allow.

- From this viewpoint, if there are too few bulls in the herd, many cows will be not inseminated and thus, the herd will not achieve its reproductive potential.

- On the other hand, if there are too many bulls in the herd, much more than needed to inseminate all the cows, the herd reproductive potential will also be wasted - the same herd would reproduce more if instead of the extra useless bulls, we would have cows.

Thus, the ideal cow-herd situation is when there are exactly as many bulls as needed to inseminate all the cows - not less and not more.

What if the mix is imperfect: how to balance the situation. In real life, the cow-bull proportion may be not ideal. In this case, from the biological viewpoint, a reasonable idea is to produce calves of different genders so as to bring the cow-bull proportion closer to the ideal one:

- if there are at present too many bulls, it is desirable to balance the situation, by making sure that the majority of newborn calves are female;

- vice versa, if there are at present too few bulls, it is desirable to balance the situation, by making sure that the majority of newborn calves are male.

How can an individual cow know that the balance is imperfect. The gender of a calf is determined by the biological processes in the cow's body. How does the cow's body know when there are too many bulls or too few bulls?

At first glance, it may seem that the cow does not have this information. However, a detailed analysis of the situation shows that a cow can get this information. 
Indeed, as we have mentioned, cows have a sixteen-hour period during which they can be inseminated. If there are sufficiently many bulls to inseminate all the cows in heat in a shorter period of time, this means that we have an excess of bulls - with fewer bulls, we would still be able to inseminate all the cows by using the remaining unused time. For example, if all the cows are inseminated during the first eight hours of their insemination period, this means that we could use half as many bulls.

In the ideal cow-bull mix, all sixteen hours of the cow's insemination period can be used. Thus, for an individual cow, the time $\Delta t$ from the moment it got into heat to the moment when it is inseminated can be any value between 0 and 16 hours. The average value of $\Delta t$ is thus about 8 hours.

If there are too many bulls, this means that, in general, all the cows in heat will be inseminated earlier than that - thus, $\Delta t$ will be, in general, smaller.

On the other hand, if there are too few bulls, this means that many cows will be not inseminated at all, and those "lucky" ones to be inseminated will be inseminated closer to the end of their insemination window. In this case, the average value of the time $\Delta t$ will be larger.

So, we arrive at the following conclusion:

- if there are too many bulls in the herd, most cows will be inseminated in the earlier part of their insemination window; while

- if there are too few bulls in the herd, most cows will be inseminated in the later part of their insemination window.

Now, we are ready to explain the above phenomenon.

\section{Our explanation.}

- When a cow gets inseminated during the earlier part of their insemination window, to the cow's organism, this is an indication that there may be too many bulls in the heard. Thus, as we have mentioned, a natural biological reaction is to decrease this dis-balance by producing mostly female calves.

- On the other hand, when the cow gets inseminated during the later part of their insemination window, to the cow's organism, this is an indication that there many be too few bulls in the heard. Thus, as we have mentioned, a natural biological reaction is to decrease this dis-balance by producing mostly male calves.

And this is exactly the phenomenon that has been observed - which we thus explained from the general system viewpoint.

\section{Acknowledgments}

This work was supported in part by the National Science Foundation grants 1623190 (A Model of Change for Preparing a New Generation for Professional Practice in Computer Science) and HRD-1242122 (Cyber-ShARE Center of Excellence). 


\section{References}

[1] T. L. Friedman, Thank You For Being Late: An Optimists' Guide to Thriving in the Age of Accelerations, Picador, New York, 2016. 